Calcium Chroride-(1) The alumina mixed with the abestos or the pumice exposes a greater surface. (2) The same bulk weighs less. (3) When it has absorbed water it does not form crystalline hydrates which "freeze" to the walls of the absorption bottle. (4) It contains no basic sub- stances which introduce an inconstant error, and therefore it need not be saturated with carbon dioxide before using.

PHOSPHORTS PENTOXIDE-The alumina becomes a hydroxide of aluminium, which is a solid and therefore does not clog the apparatus as does the phosphoric acid formed from phosphorus pentoxide.

\title{
A Rapid Method of Analysis for Dolomite and Magnesian Limestone $^{1}$
}

\author{
By S. D. Averitt
}

KENTUCKY AGRICULTURAL EXPERIMENT STATTON, LEXINGTON, KY.

$I^{\mathrm{I}}$ THE analysis of dolomite and magnesian limestone for agricultural and commercial uses, a quick, easy, and fairly accurate method of finding the amount of calcium carbonate and magnesium carbonate present is very desirable.

In this paper is given an indirect method which meets those requirements and seems to be generally applicable to that class of stones. The functions concerned are: (1) neutralizing power of the stone as calcium carbonate, A; (2) insoluble residue and ammonium precipitate, $\mathrm{B}$; (3) moisture, M. It does not involve the determination of either calcium or magnesium, and is fully as accurate and somewhat shorter than the usual differential method, which, in addition to the neutralizing power as calcium carbonate, requires the actual determination of calcium.

In the following table a summarization is given of the data obtained on 20 representative samples of magnesian limestones and dolomites:

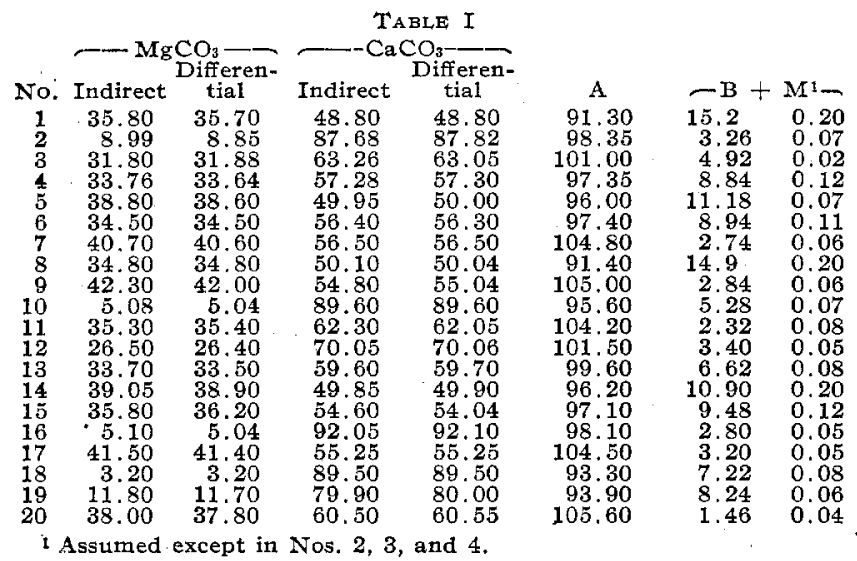

The figures for $\mathrm{MgCO}_{3}$ in the column marked "Indirect" were calculated from the equation:

$$
[\mathrm{A}-(100-(\mathrm{B}+\mathrm{M}))] 5.35=\mathrm{MgCO}_{3}
$$

which expresses the relation of magnesium carbonate $\left(\mathrm{MgCO}_{3}\right)$ to the neutralizing power of the stone as calcium carbonate, the insoluble residue and ammonium precipitate, and moisture in dolomite and magnesian limestone.

The factor 5.35 is derived as follows: Taking as known quantities $a=2.274$ and $b=1.916$, the factors for converting $\mathrm{CO}_{2}$ into $\mathrm{CaCO}_{3}$ and $\mathrm{MgCO}_{3}$, respectively, and taking as unknown quantities, $\mathrm{X}$ representing the percentage of total $\mathrm{CO}_{2}$ in the sample combined as $\mathrm{CaCO}_{3}$ and $\mathrm{Y}$ representing

1 Received September 21, 1921. Accepted October 7, 1922. Presented before the Lexington Section of the American Chemical Society, December 15, 1920. the percentage combined as $\mathrm{MgCO}_{3}$, we may write the following equations:

$$
\begin{aligned}
& a \mathrm{X}+b \mathrm{Y}=100-(\mathrm{B}+\mathrm{M}) \\
& a \mathrm{X}+a \mathrm{Y}=\mathrm{A}
\end{aligned}
$$

Solving for $\mathrm{Y}$ and getting $\mathrm{BY}\left(\mathrm{MgCO}_{3}\right)$ we have

$$
b \mathrm{Y}=\left[\mathrm{A}-\left(\frac{100-(\mathrm{B}+\mathrm{M})}{a-b}\right)\right] b
$$

Substituting for $\mathrm{BY}, \mathrm{MgCO}_{3}$, and for $\frac{b}{a-b}$ its value 5.35 , we have

$$
[\mathrm{A}-(100-(\mathrm{B}+\mathrm{M}))] 5.35=\mathrm{MgCO}_{3}
$$

Using Equation 4 in connection with the following equation: 100 Per cent $-(\mathrm{B}+\mathrm{M})=$ Per cent $\mathrm{CaCO}_{3}+$ Per cent $\mathrm{MgCO}_{3}(5)$ which is self-evident, the percentage of calcium carbonate $\left(\mathrm{CaCO}_{3}\right)$ and magnesium carbonate $\left(\mathrm{MgCO}_{3}\right)$ in the sample can be readily calculated.

A comparison of the figures in Table I for calcium carbonate $\left(\mathrm{CaCO}_{3}\right)$ and magnesium carbonate $\left(\mathrm{MgCO}_{3}\right)$ by the indirect and the differential methods shows that they are of about equal accuracy. In connection with this statement it should be noted that the calcium carbonate in the column marked "Differential" was actually determined. The method here given has been checked against the differential method on more than 50 samples of magnesian limestone containing from 3.2 per cent to 42.8 per cent $\mathrm{MgCO}_{3}$ and of varying degrees of impurity. The maximum difference was 0.5 per cent $\mathrm{MgCO}_{3}$. The average was slightly more than 0.1 per cent. This shows as close agreement as could be expected and indicates a reasonably wide applicability of the method.

\section{Details of the Experimental Procedure}

One-half gram of finely ground stone is put into a widemouth flask of 100- to 150-cc. capacity and $25 \mathrm{cc} .0 .5 \mathrm{~N} \mathrm{HCl}$ added, and the sides of the flask washed down with a little water. It is then boiled gently 5 or $10 \mathrm{~min}$., or until decomposition of $\mathrm{CaCO}_{3}$ and $\mathrm{MgCO}_{3}$ is complete. Enough hot water to maintain or slightly increase the volume is used once or twice during the boiling to wash down the sides of the flask. The solution is then cooled and the excess acid neutralized with $0.25 \mathrm{~N} \mathrm{NaOH}$, a small drop of methyl orange being used as the indicator, and the first change from pink to yellowish is taken as the end-point. Note exactly the volume of $0.25 \mathrm{~N} \mathrm{NaOH}$ required to neutralize the excess acid. To the solution add 10 cc. of 10 per cent $\mathrm{NH}_{4} \mathrm{Cl}$ solution and two drops of ammonia, heat gently until the 